\title{
The Contributing Role of Family, School, and Peer Supportive Relationships in Protecting the Mental Wellbeing of Children and Adolescents
}

\author{
Nadia Butler ${ }^{1}\left[\right.$ Zara Quigg $^{1} \cdot$ Rebecca Bates $^{1} \cdot$ Lisa Jones $^{1} \cdot$ Emma Ashworth $^{2} \cdot$ Steve Gowland $^{3} \cdot$ Margaret Jones $^{3}$
}

Accepted: 10 January 2022 / Published online: 6 February 2022

(c) The Author(s) 2022

\begin{abstract}
Globally, mental disorders are the leading cause of disability in children and adolescents. Previous research has demonstrated that supportive relationships are a key protective factor against poor mental health in children, particularly amongst those who have experienced adversity. However, fewer studies have examined the relative impact of different types of supportive relationships. The current study examined the association between level of family adult support, school adult support, and school peer support and mental wellbeing in a sample of children (age 8-15 years, $N=2,074$ ) from schools in the UK. All three sources of support were independently associated with mental wellbeing. Analyses demonstrated a graded relationship between the number of sources of support and the odds of low mental wellbeing (LMWB), reflecting a cumulative protective effect. While all three sources of support were best, it was not vital, and analyses demonstrated a protective effect of school sources of support on LMWB amongst children with low family support. Peer support was found to be particularly important, with prevalence of LMWB similar amongst children who had high peer support (but low family and school adult support), and those who had high family and school adult support, (but low peer support), indicating that high peer support has an equivalent impact of two other protective factors. Findings from the study highlight the crucial context schools provide in fostering positive peer relationships and supportive teacher-student relationships to promote mental health and resilience for all children, including both those with and without supportive home environments.
\end{abstract}

Keywords Mental wellbeing $\cdot$ Resilience $\cdot$ Family support $\cdot$ School support $\cdot$ Peer support $\cdot$ Children and adolescents

\section{Introduction}

Mental disorders are the leading cause of disability in young people globally, and at least one in five young people are estimated to experience a mental disorder in a given year (Patel et al., 2007; World Health Organization, 2012; Gore et al., 2011). In 2017, one in eight children in England had a mental disorder, and there has been an increase in the prevalence of disorders over the past two decades, particularly

Nadia Butler

n.1.butler@ljmu.ac.uk

1 Public Health Institute, Liverpool John Moores University, 3rd Floor Exchange Station, Tithebarn Street, Liverpool L2 2QP, UK

2 School of Psychology, Liverpool John Moores University, Liverpool, UK

3 Sefton Council, Sefton, UK emotional disorders (NHS Digital, 2018; Patalay \& Fitzsimons, 2017; Pitchforth et al., 2018). Untreated mental illness in childhood has profound implications across numerous domains of functioning and is associated with poor academic achievement (McLeod et al., 2012; Deighton et al., 2018), behavioural problems (Vorhaus \& Vorhaus, 2012), school exclusion and truancy (Ford et al., 2018; Wood et al., 2012; Egger et al., 2003), substance use (Kandel et al., 1997; Goodwin et al., 2004), violence (Elborgen \& Johnson, 2009; Arseneault et al., 2000), and delinquency (Sibley et al., 2011). Substantial global evidence has demonstrated that the risk of experiencing mental health difficulties across the lifecourse is strongly associated with childhood socioeconomic disadvantage, abuse and neglect, and other adversities (Edwards et al., 2003; McLaughlin et al., 2012; Hughes et al., 2016, 2019; Raposo et al., 2014; Turner et al., 2006; Dube et al., 2001). Crucially, childhood mental illness is one of the most evidenced predictors of psychiatric disorders in adulthood, with over half of all mental health difficulties in 
adulthood having their onset before the age of 14 (Fombonne et al., 2001; Reef et al., 2011; World Health Organization Regional Office for Europe, 2018). Thus, understanding the factors that both promote positive mental health in childhood and protect against mental health difficulties in children with high levels of risk is of vital importance in order to help prevent the onset of difficulties at this potentially critical point for the development of disorders.

Multiple research studies have identified the availability of stable, supportive relationships during childhood as an important determinant of mental wellbeing in childhood (Chu et al., 2010; Morgan et al., 2007) and across the whole lifecourse (Hughes et al., 2018). Social support is proposed to positively impact wellbeing as both a promotive factor (a factor which is associated with increased resilience and healthy functioning regardless of the presence of risk) and a moderator or protective factor (a factor that directly buffers against negative outcomes in individuals with high levels of risk) (Beeble et al., 2009). Studies have shown a significant association between positive supportive relationships with parents and youth's wellbeing and life satisfaction, underlining the importance of caring, supportive families in fostering all children's social and emotional wellbeing, regardless of level of risk (Gilman \& Huebner, 2003; Oberle et al., 2011). Furthermore, positive social relationships develop individual level capacities, such as social competencies and self-esteem, which are promotive factors and essential for good mental health across the lifecourse for all individuals (Bagwell et al., 1998; Hartup, 1989). Crucially, such supportive relationships protect against the toxic effects of extreme stress on development by providing high risk children with a safe space to recover and develop healthy stress response systems (National Scientific Council on the Developing Child, 2015). Retrospective studies with adults suggest that social support (e.g. trusted adult support and positive peer relationships) in childhood is associated with lower levels of mental illness in adulthood for both those with and without childhood adversity (Hughes et al., 2018). For example, warm, supportive parenting has been demonstrated to mitigate the impact of family financial difficulty on mental health difficulties in early and middle childhood, with high levels of supportive parent-child interaction a more important predictor of child development than measures of disadvantage (e.g. parental education or income) (Sylva et al., 2008; Kirby et al., 2020).

While supportive relationships typically begin in the family, and attachment to a primary caregiver is argued to have one of the most salient influences on a child's development (Ainsworth \& Bell, 1970; Bowlby, 1982; Harlow, 1958), findings from a longitudinal study have demonstrated that, beyond immediate family members, the most frequent positive role model, or trusted adult, in children's lives is a teacher (Werner \& Smith, 1989). Supportive relationships between students and their teachers have been found to positively influence children's school engagement and achievement, social skills, problem-solving skills, and sense of purpose and autonomy (Morrison \& Allen, 2007; Sharkey et al., 2008; Woolley \& Bowen, 2007), all of which are promotive and protective factors. Furthermore, household and family dysfunction, in addition to exposure to more severe forms of abuse and neglect, is likely to disrupt parent-child relationships. Thus positive and supportive relationships with teachers may be even more crucial for children who experience adversity as they are less likely to have supportive relationships within the family environment (Levendosky et al., 2002; Morton \& Browne, 1998; Werner, 2005; Zimrin, 1986; Hughes et al., 2018; Heard-Garris et al., 2018). Previous research has shown that high levels of support from any trusted adult in childhood, regardless of relationship, halves the prevalence of low mental wellbeing amongst adults who experienced high levels of childhood abuse and adversity, compared to those who experienced adversity but no such adult support (Bellis et al., 2017).

School peers can also be an important contributor to resilience, developing social competencies, building selfesteem, and providing a source of emotional and practical support (Hartup \& Stevens, 1999). Friendships characterized by high social support and acceptance are associated with lower levels of mental health difficulties and behavioural problems (Rothon et al., 2011; McPherson et al., 2014). Evidence also demonstrates that peer relationships moderate the association between family adversity and child maladjustment (Criss et al., 2002; Schwartz et al., 2000; Malindi \& Machenjedze, 2012). However, research is currently limited on the impact of such relationships on child mental health outcomes (Sharkey et al., 2008; Bellis et al., 2018). In addition to teacher and peer relationships moderating associations between family adversity and child maladjustment in at-risk children, emerging evidence suggests that positive relationships may function in an additive manner, with social support from peers, teachers, and other trusted adults reinforcing pre-existing positive developmental pathways in children with positive family relationships (Criss et al., 2002). Thus, substantial debate in the field exists regarding both the relative importance of different sources of support (e.g. family, teacher, and peer) on a range of child developmental factors (Laible \& Thompson, 2007; Collins et al., 2000; Harris, 1995; Criss et al., 2002), whether support functions in an additive manner, and whether it is a promotive and/or protective factor (Criss et al., 2002).

\section{The Current Study}

A large evidence base demonstrates the association between supportive relationships and mental health in children and adults, particularly amongst those who have experienced 
adversity; however, fewer studies have explored the relative impact of different types of supportive relationships. Thus, the current study aims to contribute to the existing evidence base by:

1. Determining whether different sources of social support, including family adult support, school adult support, and school peer support, are associated with mental wellbeing in children and adolescents;

2. Exploring whether the number of sources of support available is associated with mental wellbeing; and,

3. Examining whether school sources of support (i.e. adult support and peer support) function as promotive or protective factors against poor mental wellbeing in children and adolescents with and without family adult support.

\section{Methods}

\section{Study Design and Procedure}

The current study used a cross-sectional non-probability sampling design. All schools in a borough of the North West of England were contacted by the public health lead from the borough council ${ }^{1}$ and invited to take part in an online survey measuring levels of pupils' mental wellbeing and resilience. Principals who wished for their school to take part in the study acted as gatekeepers, and upon return of their signed consent form to the research team were provided with a letter, a detailed information sheet and both opt-in and opt-out parent/caregiver consent forms. Principals were asked to use their own discretion to decide on the method of consent most appropriate to the year groups they planned on implementing the survey with. Schools were also provided with standard text about the aims and reasons for the study and a link to a website with study information. This information about the study could be provided to parents if schools chose not to provide them with an opt-in/opt-out option via a school website, newsletter, email, or letters home. Principals of participating schools were asked to provide written consent in loco parentis for children whose parents did not contact them to opt-out of the study or if the principal chose not to send out opt-out forms.

Child friendly participant information sheets were provided at the beginning of the survey to participating children, with separate age-appropriate information sheets provided for primary and secondary school children. Implied assent from children was taken on commencement of the

\footnotetext{
${ }^{1}$ Local government responsible for a wide range of statutory and non-statutory services, including for example, education and social care services.
}

survey. Participating children completed a developmentally appropriate, anonymous, online questionnaire on school computers on their own, on a whole class basis, supervised by a school teacher. Non-participating students were assigned other appropriate work to complete by the teacher. There were years of focus in which principals were encouraged to administer the surveys (Year 4 [age 8-9 years], Year 7 [11-12 years], and Year 9 [13-14 years] students ${ }^{2}$ ), but they were free to administer the surveys to students of any year group (but no younger than Year 3 [age 7-8 years] $]^{3}$ ). In secondary schools, where students attend courses with multiple teachers, principals were asked to ensure that the survey was implemented during just one subject course in order to avoid duplicating responses and students answering the survey in multiple courses. Ethical approval for the study was granted from Liverpool John Moores University Research Ethics Committee and the study was also reviewed and passed by the borough's public engagement and consultation panel.

\section{Sample}

Data were collected from 2074 children from 22 primary (ages $8-11$ years, $n=1,280$ ) and 5 secondary (age $11-15$ years, $n=794$ ) schools across a borough in North West England. The total number of students in participating schools was 12,153 ; thus, the study sample represented $17.1 \%$ of all students from participating schools. ${ }^{4}$ Information on the number of students who opted out was unavailable, nor was information available on the total number of students in each year group of participating schools; thus, calculating an exact response rate by participating year group was not possible. The mean age of participants was 10.4 years (range $8-15$ years, $\mathrm{SD}=2.02$ ). Approximately equal numbers of males $(51.4 \%, n=1066)$ and females $(48.6 \%, n=1008)$ participated in the survey.

\section{Measures}

Final measures selected for inclusion were drawn from Public Health England guidance on measuring mental health and wellbeing in students, and measures used have been demonstrated to be suitable for use by children and are considered feasible in a school setting (i.e. not too long or requiring specific equipment) (Public Health England, 2016). Extensive consultation with school representatives, including

\footnotetext{
${ }^{2}$ Equivalent to USA 3rd, 6th and 8th Grades.

${ }^{3}$ Equivalent to USA 2nd Grade.

${ }^{4}$ The total number of students at participating schools includes students from Year 1 and Year 2, who were ineligible to participate in the study.
} 
principals, mental health leads, school nurses, and a community mental health team was undertaken about the content and methodology of the measures to ensure questions supported wider trauma-informed practices being implemented across the area.

\section{Sources of Support}

The Student Resilience Survey is a 47-item measure comprising 12 subscales measuring students' perceptions of their individual characteristics as well as protective factors embedded in the environment (Lereya et al., 2016). Three subscales measuring supportive relationships in the family, school, and peer groups were used in the current study. The family and school support scales refer to an adult at home or school, respectively, and each includes four items (e.g. at home/at school there is an adult who... is interested in my school work; believes that I will be a success). The peer support scale included 10 items, drawn from the original 12-item scale, ${ }^{5}$ referring to aspects of support and friendship with other children at school (e.g. are there children at your school who would... tell you you're their friend; help you if you hurt yourself). Items were scored on a 5-point scale $(1=n e v e r$ to $5=$ always $)$. Total scores on each scale were dichotomized to represent high and low levels of support, with low support defined as $>1$ standard deviation below the mean (low family support scores $<15.12[M=17.54$, $\mathrm{SD}=2.42]$, low school support scores $<12.58[M=16.11$, $\mathrm{SD}=3.53]$, and low peer support scores $<31.20[M=39.41$, $\mathrm{SD}=8.21]$ ). The Student Resilience Survey has previously been validated in a sample of UK primary and secondary school children, and good internal consistency was found for all subscales (family support subscale, $a=0.80$; school support subscale, $a=0.89$; peer support subscale, $a=0.93$ ) (Lereya et al., 2016).

\section{Mental Wellbeing}

Mental wellbeing was measured in the current study using age-appropriate standardized measures: the Warwick

\footnotetext{
5 After consulting with relevant stakeholders, there was consensus that the peer support scale, which contained 12 items, could potentially be distressing for children without such peer support. Stakeholders acknowledged the importance of measuring levels of support across the three domains, however from a trauma-informed perspective, they requested the subscale was shortened to lessen the potential impact on students with fewer friends. The removed items included: "are there students at your school who would... (1) pick you on their team, and (2) tell you secrets". These questions were decided on by stakeholder consensus because the majority argued that not all children are good at activities involving teams and this may be why they are not selected, and telling secrets was considered something that should not be encouraged.
}

Edinburgh Mental Wellbeing Scale (WEMWBS) (for secondary school participants aged $11+$ years) and the Stirling Children's Wellbeing Scale (SCWBS) (for primary school participants aged 8-11 years). The SCWBS and WEMWBS measure similar components of wellbeing using a positive and holistic approach, and there is a significant strong positive correlation between the two measures indicating construct validity (Liddle \& Carter, 2013). WEMWBS is a 14-item scale measuring mental wellbeing in the general population which has been validated with English and Scottish children aged 13 years and above, with findings demonstrating the scale measures one strong underlying factor and has good internal consistency ( $a=0.87$ ) (Clarke et al., 2010). While it has not been validated with younger children, it has been used in previous research with children aged 11 years and above (Public Health England, 2016). WEMWBS was used with all participating secondary school children (aged 11+ years) in the current study. The scale consists of a series of statements about feelings and thoughts (e.g. I've been feeling useful; I've been feeling loved) and participants are asked to select the answer to each statement which best describes their experience over the past two weeks. Responses are scored on a 5-point scale $(1=$ none of the time to $5=$ all of the time), resulting in a minimum score of 14 and maximum score of 70. Total scores on WEMWBS were dichotomized to define low mental wellbeing as $>1$ standard deviation (12.09) below the mean (48.14); thus, low mental wellbeing was operationalized as scores $<36.05$.

SCWBS is a 12-item scale measuring emotional and psychological wellbeing suitable for children aged 8-15 years. SCWBS was used in the current study with all participating primary school children (aged 8-11 years). It has previously been validated in Scottish children and findings demonstrated the scale had good internal reliability $(a=0.85)$, construct validity and external reliability, and appeared to be a robust measure of wellbeing in younger children (Liddle \& Carter, 2015). The scale consists of two subscales comprising 6 items each, which provide scores for positive emotional state (e.g. I've been feeling calm) and positive outlook (e.g. I think lots of people care about me), the sum of which can be calculated to determine a total wellbeing score. Participants are asked to select the response to each statement which best describes their thoughts and feelings over the past couple of weeks. Responses are scored on a 5 -point scale $(1=$ never to $5=$ all of the time $)$, resulting in a minimum score of 12 and maximum score of 60 . Total scores on SCWBS were dichotomized to define low mental wellbeing as $>1$ standard deviation (9.02) below the mean (45.82), thus low mental wellbeing was operationalized as scores $<36.83$.

A new mental wellbeing variable $(1=$ low mental wellbeing, $0=$ high mental wellbeing) for all participants was created by combining relevant cut-off scores 
Table 1 Bivariate and unadjusted relationships between sources of support and gender, and low mental wellbeing

\begin{tabular}{|c|c|c|c|c|c|c|c|}
\hline & \multicolumn{7}{|c|}{ Low mental wellbeing } \\
\hline & \multirow[t]{2}{*}{$n$} & \multirow[t]{2}{*}{$\%$} & \multirow[t]{2}{*}{$\chi^{2}$} & \multirow[t]{2}{*}{$p$} & \multirow[t]{2}{*}{$O R$} & \multicolumn{2}{|c|}{$95 \% \mathrm{CIs}$} \\
\hline & & & & & & $L L$ & $U L$ \\
\hline \multicolumn{8}{|l|}{ Gender } \\
\hline Male & 222 & 23.0 & & & Ref & & \\
\hline Female & 280 & 30.2 & 12.106 & $<0.001$ & 1.45 & 1.18 & 1.78 \\
\hline \multicolumn{8}{|c|}{ Family adult support } \\
\hline High & 339 & 21.6 & & & Ref & & \\
\hline Low & 163 & 50.8 & 115.256 & $<0.001$ & 3.75 & 2.92 & 4.82 \\
\hline \multicolumn{8}{|c|}{ School adult support } \\
\hline High & 316 & 20.3 & & & Ref & & \\
\hline Low & 186 & 55.2 & 171.205 & $<0.001$ & 4.83 & 3.77 & 6.19 \\
\hline \multicolumn{8}{|c|}{ Peer adult support } \\
\hline High & 313 & 19.7 & & & Ref & & \\
\hline Low & 189 & 61.6 & 228.800 & $<0.001$ & 6.51 & 5.02 & 8.46 \\
\hline
\end{tabular}

OR odds ratio, $95 \%$ CIs $95 \%$ confidence intervals, $L L$ lower limit, $U L$ upper limit, Ref. reference category on WEMWBS $(<36.05)$ for secondary school children or SCWBS $(<36.83)$ for primary school children.

\section{Statistical Analysis}

Data were analysed with SPSS v.26. Analyses employed chi square for independence with continuity correction for initial bivariate examination of associations between mental wellbeing and sources of support and gender. An independent samples t-test was used to examine the association between mental wellbeing and age. Multivariate modelling used binary logistic regression to examine the independent relationships between family adult, school adult, and school peer support, and gender and age, with mental wellbeing. As the assessed relationships are clustered within schools, the nature of the data is inherently hierarchical and characteristics of the school may influence the results. To control for this, multivariate models were tested using linear mixed modelling to consider cluster random effects. The intraclass correlation coefficient (Bickel, 2007) was 0.175 , indicating that approximately $17 \%$ of the variability in mental wellbeing was due to the school the participant attended and thus a multilevel analysis was justified (Kreft \& de Leeuw, 1998). The effects of sources of support on mental wellbeing were assessed with random effects specified in these analyses, which consisted of adjusting errors for clustering at school level with a random intercept model. Modelled estimates for prevalence of low mental wellbeing were calculated for different levels and combinations of sources of support using an estimated marginal means function to adjust estimates for age and gender (IBM, 2017).

\section{Results}

Overall, over one quarter $(26.5 \%, n=502)$ of participants had low mental wellbeing (LMWB). There was a significant association between mental wellbeing, and age and gender. Those with LMWB were older $(M=11.5$ years, $\mathrm{SD}=2.1)$ than those who did not have LMWB $(M=9.9$ years, $\mathrm{SD}=1.8, p<0.001)$. A higher proportion of females had LMWB compared to males (Table 1).

\section{Sources of Support and Mental Wellbeing}

Approximately one-sixth of participants had a low level of family adult support (FAS; $17.1 \%, n=354$ ), school adult support (SAS; $18.8 \%, n=389$ ), and school peer support (SPS; $17.9 \%, n=372$ ). There was a significant association between LMWB and levels of support across all three categories (FAS, SAS, and SPS) (Table 1). In multivariate analysis, when all forms of support, gender, and age were included in the model, all variables remained independently associated with LMWB (Table 2). Low levels of each type of support were significantly associated with increased odds of LMWB (Table 2). Female students had significantly higher odds of LMWB compared to males, independent of level of different sources of support, and the odds of LMWB increased as age increased (Table 2).

\section{Level of Support and Mental Wellbeing}

Overall, almost two-thirds $(63.6 \%, n=1319)$ of participants had a high level of support from all three sources. Approximately one quarter $(23.2 \%, n=479)$ of participants had a high level of support from two sources, $9.3 \%(n=192)$ had 
Table 2 Adjusted relationships between sources of support, gender and age, and low mental wellbeing

\begin{tabular}{lllll}
\hline & \multicolumn{4}{l}{ Low mental wellbeing } \\
\cline { 2 - 4 } & $A O R$ & \multicolumn{2}{l}{$95 \%$ CIs } & $p$ \\
\cline { 2 - 4 } & & $L L$ & $U L$ & \\
\hline Low family adult support & 2.69 & 2.00 & 3.61 & $<0.001$ \\
Low school adult support & 2.08 & 1.54 & 2.80 & $<0.001$ \\
Low school peer support & 6.64 & 5.16 & 8.54 & $<0.001$ \\
Female gender & 1.96 & 1.44 & 2.67 & $<0.001$ \\
Age & 1.35 & 1.23 & 1.49 & $<0.001$ \\
\hline
\end{tabular}

AOR adjusted odds ratio, 95\% CIs $95 \%$ confidence intervals, $L L$ lower limit, $U L$ upper limit.

${ }^{\text {a}}$ Reference category $=$ male

Table 3 Adjusted relationships between number of high level sources of support, gender and age, and low mental wellbeing

\begin{tabular}{|c|c|c|c|c|}
\hline & \multicolumn{4}{|c|}{ Low mental wellbeing } \\
\hline & \multirow[t]{2}{*}{ AOR } & \multicolumn{2}{|c|}{$95 \% \mathrm{CIs}$} & \multirow[t]{2}{*}{$p$} \\
\hline & & LL & UL & \\
\hline \multicolumn{5}{|c|}{ Number of high level sources of support } \\
\hline Three & & & & Ref \\
\hline Two & 4.01 & 3.18 & 5.15 & $<0.001$ \\
\hline One & 13.15 & 8.35 & 20.70 & $<0.001$ \\
\hline None & 17.96 & 9.92 & 32.56 & $<0.001$ \\
\hline \multicolumn{5}{|l|}{ Gender $^{a}$} \\
\hline Female & 1.84 & 1.35 & 2.49 & $<0.001$ \\
\hline Age & 1.30 & 1.20 & 1.42 & $<0.001$ \\
\hline
\end{tabular}

AOR adjusted odds ratio, $95 \%$ CIs $95 \%$ confidence intervals, $L L$ lower limit, $U L$ upper limit, Ref. reference category

${ }^{a}$ Reference category male

Fig. 1 Adjusted proportion (95\% CIs) of children with low mental wellbeing by number of high level sources of support

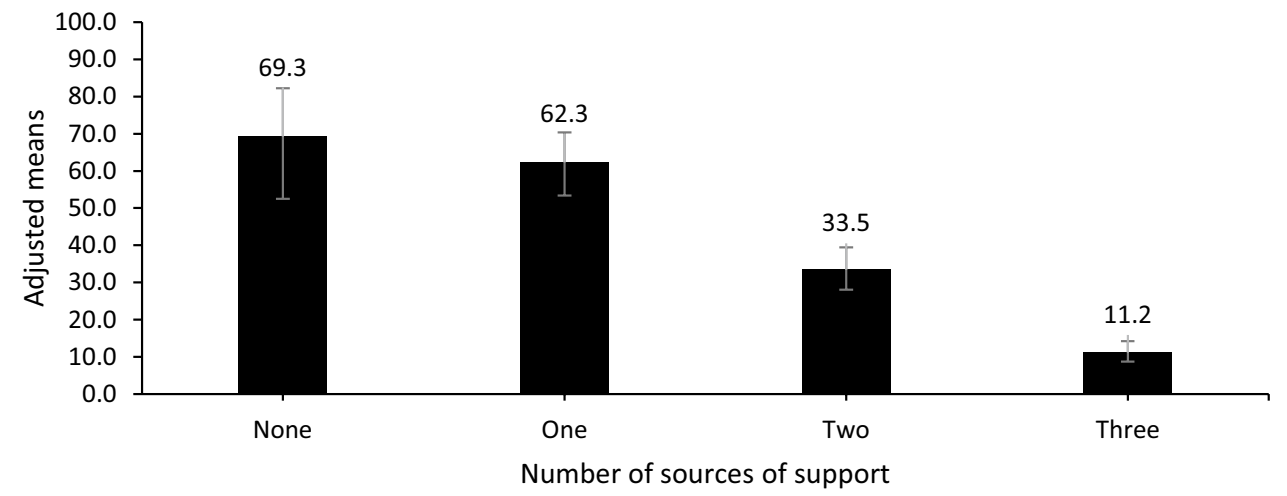

times higher for those with low school adult only, low family adult support only, and low peer support only, respectively, and seven times higher for those with high peer support only (Table 4). However, the combination of low peer support

Number of sources of support a high level of support from one source, and $4.1 \%(n=84)$ of participants had no high level of support from any of the three sources.

In multivariate analysis after adjusting for age and gender, there was a significant association between the number of sources and mental wellbeing, with a graded relationship between the number of high level sources of support and odds of LMWB (Table 3). The odds of LMWB were over 17,13 , and four times higher for those with no high level sources of support, one source or two sources, respectively, compared to those with the high level of support from all three sources (Table 3). Modelled prevalence estimates reflect these findings, with the lowest prevalence of LMWB amongst those with all three sources of support at a high level, and increasing prevalence of LMWB as number of sources of support decreased (Fig. 1).

\section{School Sources of Support in Children and Adolescents With and Without Family Support}

In bivariate analysis, there was a strong relationship between level of FAS and SAS $\left(\chi^{2}=147.037, p<0.001\right)$; level of FAS and SPS $\left(\chi^{2}=123.339, p<0.001\right)$; and level of SAS and SPS $\left(\chi^{2}=169.236, p<0.001\right)$. Due to these strong relationships and to meet study objectives of exploring the association between mental wellbeing and different sources of support, for multivariate analyses, the individual support variables were combined to create a new overarching sources of support variable. Participants were then categorized into the following groups: high overall support (high FAS, SAS, and SPS), low overall support (low FAS, SAS, and SPS), high FAS only (low SAS and SPS), high SPS only (low FAS and SAS), high SAS only (low SPS and FAS), low FAS only (high SPS and SAS), low SPS only (high FAS and SAS), and low SAS only (high FAS and SPS).

In multivariate analyses, after accounting for the effects of age and gender, the combined support variable was significantly associated with mental wellbeing. Compared to those with high overall support, LMWB was two, three, and eight 
Table 4 Adjusted relationships between level of different sources of support, gender and age, and low mental wellbeing

Fig. 2 Adjusted proportion (95\% CIs) of children with low mental wellbeing by level of family adult support and school adult and peer support

\begin{tabular}{lllllll}
\hline Family adult support & $\begin{array}{l}\text { School peer } \\
\text { support }\end{array}$ & $\begin{array}{l}\text { School adult } \\
\text { support }\end{array}$ & \multicolumn{2}{l}{ Low mental wellbeing } \\
\cline { 5 - 6 } & & & AOR & $95 \%$ CIs & $p$ \\
\cline { 5 - 6 } & & & & LL & UL & \\
\hline High & High & High & Ref & & & \\
High & High & Low & 2.44 & 1.73 & 3.43 & $<0.001$ \\
High & Low & High & 8.45 & 6.17 & 11.57 & $<0.001$ \\
High & Low & Low & 18.25 & 9.20 & 36.22 & $<0.001$ \\
Low & High & High & 3.42 & 2.47 & 4.73 & $<0.001$ \\
Low & High & Low & 7.54 & 4.17 & 13.64 & $<0.001$ \\
Low & Low & High & 20.14 & 10.93 & 37.11 & $<0.001$ \\
Low & Low & Low & 18.69 & 10.24 & 34.12 & $<0.001$ \\
Female gender & & & 1.97 & 1.43 & 2.70 & $<0.001$ \\
Age & & & 1.35 & 1.22 & 1.49 & $<0.001$ \\
\hline
\end{tabular}

AOR adjusted odds ratio, $95 \%$ CIs $95 \%$ confidence intervals, $L L$ lower limit, $U L$ upper limit, Ref reference category

${ }^{\mathrm{a}}$ Reference category $=$ male

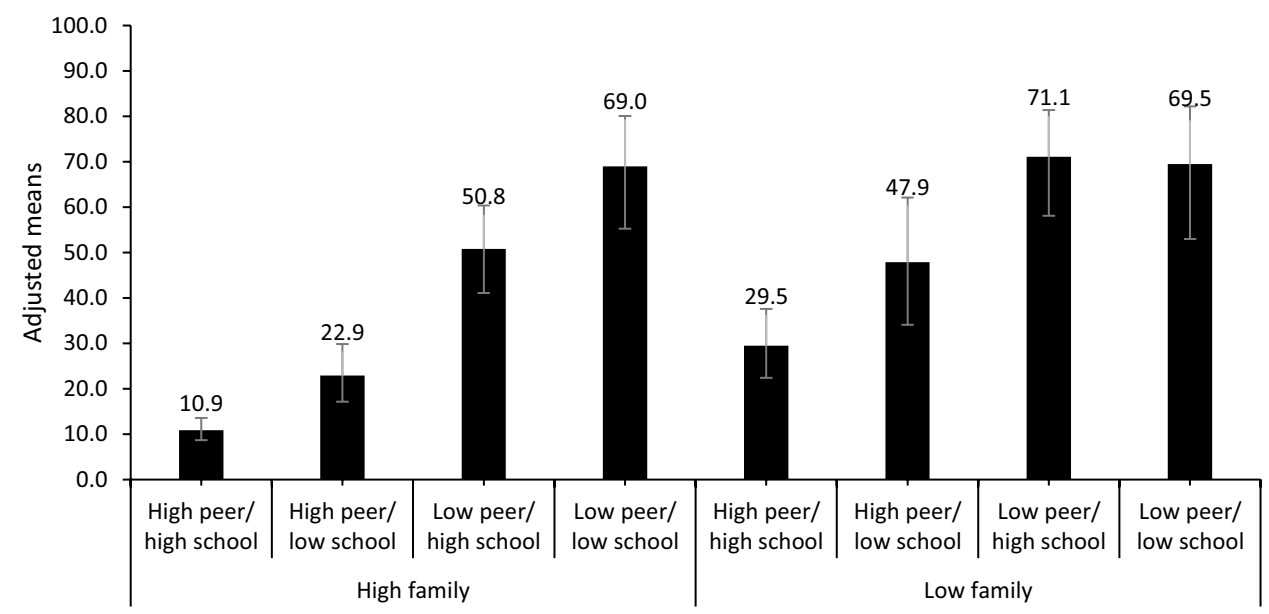

with low family and/or school adult support was associated with the highest increase in odds of LMWB (Table 4). Those with low overall support or with high family support only were over 18 times more likely to have LMWB compared to those with high overall support, while those with high school adult support only were over 20 times more likely to have LMWB (Table 4).

Modelled prevalence estimates reflect these findings with the lowest prevalence of LMWB amongst those with high overall support, with only $10.9 \%$ experiencing LMWB (Fig. 2). Prevalence of LMWB increased amongst those with low school adult support only and amongst those with low family support only to $22.9 \%$ and $29.5 \%$, respectively (Fig. 2). Amongst those with high peer support only, and those with high school adult support only, prevalence of LMWB increased to $47.9 \%$ and $50.8 \%$, respectively (Fig. 2). The highest prevalence of LMWB was amongst those with a combination of low peer support and low adult support (either family and/or school), with approximately $70 \%$ of individuals experiencing LMWB (low SPS and SAS group (69.0\%), as well as the low SPS and FAS group (71.1\%), and the low overall support group (69.5\%); Fig. 2).

\section{Discussion}

The purpose of the current study was to examine the association between different sources of support and mental wellbeing in children and adolescents. Findings indicated that family adult support, school adult support, and school peer support were all independently associated with mental wellbeing in children and adolescents. This suggests that all three sources of support are protective factors for wellbeing. Findings from the current study are consistent with previous research that demonstrates the association between supportive relationships and mental wellbeing (Hughes 
et al., 2018; Hartup, 1989). However, much of the previous literature focuses on the protective effect of having access to any one trusted adult in childhood (Bellis et al., 2017; Whitehead et al., 2019). Our study shows that school adult support and family adult support are independently associated with LMWB and function in an additive manner. Thus, having access to an adult both at home and in school provides a greater protective effect against LMWB than either one alone. Findings showed that amongst children with high peer support, when levels of either school or family support were low, prevalence of LMWB was approximately the same at $22.9 \%$ and $29.5 \%$, respectively. When both family and school adult support were low, prevalence of LMWB rose to $47.9 \%$. This is consistent with previous research in schools, which has shown that teachers and parents have independent impacts on student engagement and achievement (Brewster et al., 2007; Hughes \& Kwok, 2007; Sylva et al., 2008). A study of European American school students by Wentzel (1998) found that the roles of teachers and parents worked in an additive way to promote student functioning and provided unique contributions to children's level of engagement, with parental support associated with students' academic goal orientations, whereas teacher support was related to interest in class and pursuit of goals. Thus safe, secure, and supportive home and school environments are both required for children and adolescents to develop and thrive (World Health Organization Regional Office for Europe, 2018).

While all sources of support were independently associated with mental wellbeing, findings from our study showed having all three sources of support was associated with the lowest prevalence of LMWB. Our analysis also demonstrated a graded relationship between the number of sources of support and the prevalence of LMWB in children and adolescents. Specifically, the prevalence of LMWB tripled when sources of support reduced from three to two and doubled when the number of sources of support reduced from two to one or none. This exponential relationship between sources of support and LMWB reflects a cumulative protection effect. Many models on cumulative risk exist and research has shown that the number of risk factors a child has is often more important than the nature of the risk factors in likelihood of poor outcomes (Ashworth \& Humphrey, 2020). Our study demonstrates that protective factors such as supportive relationships may similarly provide a cumulative protective effect on mental wellbeing. Evidence for a cumulative protective effect has been found in previous studies of other outcomes such as youth violence (Stoddard et al., 2013), delinquency (Yoshikawa, 1994), and drug and alcohol use (Ostaszewski \& Zimmerman, 2006).

While our study found that having all three sources of support was best and resulted in the lowest prevalence of LMWB, it was not vital, and analyses demonstrated a protective effect of school sources of support on LMWB amongst children with low levels of family support. While prevalence of LMWB was only $10.9 \%$ amongst children with high family, school, and peer support, amongst children with low family support, the prevalence of LMWB was $29.5 \%$ if school and peer support was high, but $69.5 \%$ if school and peer support was low. Further, if peer support and family support was high, prevalence of LMWB was $22.9 \%$, suggesting that peer support plus the addition of one supportive adult, either at home or in school, has an approximate equivalent protective effect. This has important implications for children with low family support, where supportive adult relationships at school can compensate and protect against negative outcomes and is in line with previous studies of the protective impact of any type of adult support (Bellis et al., 2017). Poor family support and relationships have been associated with increased risk of child abuse and neglect, which is a positive predictor for poorer outcomes across the lifecourse, including mental health problems (Stith et al., 2009; Lindert et al., 2014; Chandon et al., 2019; Alm et al., 2020; Hughes et al., 2020; Butler et al., 2020). This highlights that the protective effect of school sources of support against LMWB could be crucial for children with low family support. However, evidence shows that adversity in childhood can lead to behavioural problems in school and is linked with increased likelihood of leaving school early, either voluntarily or through exclusion (Fry et al., 2018; Hardcastle et al., 2018; Jimenez et al., 2015). Furthermore, mental health problems are associated with disruptive behaviour, truancy, and low academic achievement, which further increases the risk of exclusion from school (NHS Digital, 2018; Paget et al., 2018). Thus, those potentially most at risk of exclusion are also those who might most need school sources of support to reduce risk of LMWB (and other negative outcomes). This suggests that a trauma-informed approach in schools could be beneficial, where staff are trained to understand how adversity can affect student learning and behaviour, and address this by providing alternative sources of support, such as peer and teacher relationships, to develop resilience and overcome adversity, rather than taking traditional punitive approaches to misbehaviour.

Study findings also suggested that peer support might be the most important protective factor against low mental wellbeing. After adjusting for age and gender, and controlling for family support and school adult support, children with low peer support were over six times more likely to experience low mental wellbeing. Furthermore, although we generally found a cumulative protection effect, where an increased number of sources of support was associated with an incremental decrease in prevalence of LMWB, when we examined the specific combinations of sources of support the importance of peer support was highlighted. The prevalence of LMWB was similar amongst children who had both low family and school support but high peer support (47.9\%) to 
the prevalence in children who have high family and school support but low peer support (50.8\%). This indicates that high peer support has an equivalent impact of two other protective factors: family support and school adult support, on mental wellbeing. This finding is in line with other studies, which have found that positive peer relationships can serve as protective factors for children at risk due to family adversity (Criss et al., 2002; Schwartz et al., 2000).

One possible explanation for these findings is that different types of relationships may meet different needs, thus why all three sources of support is best (Oldfield et al., 2016; Wentzel, 1998). However, in at-risk children where needs are not being met in a particular relationship context (e.g. at home), children may find other relationships (e.g. amongst peers) which meet these needs (Price, 1996). Evidence suggests that peer relationships are important developmental factors in shaping young people's attitudes, behaviour, and identity, and developing self-esteem and social competence (Rubin, 1990; Reitz et al., 2014). Thus, positive peer relationships may function as a 'remedial' socialization context in at-risk children to develop skills not learned at home (Criss et al., 2002; Price, 1996). Furthermore, positive peer role models may function as a type of behavioural intervention for children who have been exposed to negative experiences in the home (Criss et al., 2002). For example, children exposed to harsh parenting and corporal punishment are at risk of developing externalizing behaviours and inappropriate ways of communicating and behaving with others (Lorber et al., 2011; Mendez et al., 2017). Positive peer role models may act as buffers and counteract and modify this behaviour learnt at home by teaching the child more prosocial means of interacting with others (Busching \& Krahe, 2020). This would suggest that school-based peer support interventions would be effective in developing such relationships, strengthening resilience, and protecting against mental health problems. Peer support interventions are particularly suited to a school setting and involve students providing support or education to other young people in their school, often a younger year group. Such interventions are versatile in nature and can include peer mentoring, peer mediation, peer counselling, befriending, and buddying and focus on a range of issues such as bullying, violence, mental health, and school transitions (King \& Fazel, 2019). While data suggest that most English primary and secondary schools use some kind of formal peer support scheme (Houlston et al., 2009), further research is needed to determine the effectiveness of peer-led interventions on mental health outcomes in school settings (King \& Fazel, 2019).

The findings in the current study should be interpreted in light of a number of limitations. While analysis demonstrated associations between different sources of support and mental wellbeing, the cross-sectional study design prevents determination of the direction of the relationship. Thus, it cannot be said whether children with mental health issues have more difficulties forming relationships with family, teachers, and peers, or even whether they simply perceive these relationships as less supportive compared to children without such difficulties, or whether children with less support across a number of domains are at increased risk of low mental wellbeing. Data on deprivation and other child and school level factors, which may be potential mechanisms for the association between sources of support and wellbeing, were not included in the current study; however, variation between schools was accounted for in our mixed modelling analysis. Further, while we controlled for age and gender in the analysis, this may have obscured potential differences in the impact of different sources of support on mental wellbeing depending on the developmental stage of the child (e.g. middle childhood vs. adolescence) and gender. The current sample did not lend itself to exploring these factors and is an important area for future research. Two items were removed from the Peer Support Scale following stakeholder consultation and in line with trauma-informed practices across the region, and this may have had an impact on the subscale's psychometric properties and resultant findings. Finally, the current study used a convenience sample and no data was available regarding the number and characteristics of those who did not participate in the study. Therefore, the study could have inadvertently excluded children with poorer supportive relationships (poor parent/teacher relationship making them more likely to be withdrawn from the study), or children who may have already been excluded from school who may have poor relationships and/or more likely to have low mental wellbeing.

\section{Conclusion}

Mental health is a key target in the United Nations Sustainable Development Goals (SDGs) and the need to look beyond the health sector to tackle the causes of poor mental health is increasingly being recognized (United Nations, 2018). Findings from the current study highlight the crucial role schools can play in fostering positive relationships amongst students and supportive teacher-student relationships to promote mental health and resilience for all children, including both those with and without supportive home environments. Considering that not only do children and adolescents account for a large proportion of the burden of global mental disease, but that poor mental health in childhood is one of the most evidenced-based predictors of psychiatric disease as an adult, preventing childhood mental health problems could be key to achieving the SDG Goal 3 (ensuring health lives and promoting wellbeing for all at all ages). While many individual schools are now beginning to adopt a trauma-informed approach and/or implement 
interventions such as peer support programmes, for this to be scalable to a national level it may require legislation and allocation of funding to schools that are designated specifically for mental health provision. The UK government is currently considering a Bill (Schools (Mental Health and Wellbeing) Bill) to amend the Education Act 2002, which will make provision for state-maintained schools to promote the mental health and wellbeing of their pupils alongside academic attainment (UK Parliament, 2020). Such legislation would ensure schools are formally recognized as more than just places of learning and supported in their role in developing other crucial competencies necessary for children and adolescents to develop and thrive. This emphasis on student mental health and wellbeing may be crucial now more than ever, and findings from the current study take on particular relevance in light of current circumstances, with schools across the world returning following disruptions and closures due to the COVID-19 pandemic. Much of the focus by stakeholders in the education sector has been on "catching up' with missed education and curriculum; however, findings from our study would suggest that promoting mental health through re-establishing positive, trusting relationships amongst peers and between students and teachers should be as important a priority going forward.

Acknowledgements We are grateful to the head teachers and teachers who contributed to the design and implementation of the survey, and to all the children, staff, and schools who took the time to participate in the survey. We are also grateful to Sefton Council for funding the study, and colleagues at the Public Health Institute, particularly Lorna Porcellato and Kim Ross-Houle for advising on initial study design, and Chloe Smith for proofing the final manuscript.

Authors' contributions NB designed the study, analysed the data, and wrote the manuscript. ZQ and LJ contributed to study design. RB supported survey implementation and data analysis. SG and MJ supported survey implementation. All authors read and approved the final manuscript.

Funding The study was funded by Sefton Council.

Availability of Data and Materials Data used in the current study are available upon reasonable request.

\section{Declarations}

Conflict of interest The authors declare that they have no conflict of interest.

Ethical approval Formal ethical approval was granted from Liverpool John Moores University Research Ethics Committee and the study was also reviewed and passed by Sefton Public Engagement and Consultation Panel. All procedures performed in studies involving human participants were in accordance with the 1964 Helsinki Declaration and its later amendments or comparable ethical standards.

Consent to participate Informed consent was obtained from legal guardians/parents or from the school gatekeeper in loco parentis.
Informed assent was also obtained from all children and adolescents who participated in the study.

Open Access This article is licensed under a Creative Commons Attribution 4.0 International License, which permits use, sharing, adaptation, distribution and reproduction in any medium or format, as long as you give appropriate credit to the original author(s) and the source, provide a link to the Creative Commons licence, and indicate if changes were made. The images or other third party material in this article are included in the article's Creative Commons licence, unless indicated otherwise in a credit line to the material. If material is not included in the article's Creative Commons licence and your intended use is not permitted by statutory regulation or exceeds the permitted use, you will need to obtain permission directly from the copyright holder. To view a copy of this licence, visit http://creativecommons.org/licenses/by/4.0/.

\section{References}

Ainsworth, M. D., \& Bell, S. M. (1970). Attachment, exploration, and separation: Illustrated by the behavior of one-year-olds in a strnge situation. Child Development, 41(1), 49-67. https://doi. org/10.2307/1127388

Alm, S., Laftman, S. B., Sivertsson, F., \& Bohman, H. (2020). Poor family relationships in adolescence as a risk factor of in-patient psychiatric care across the life-course: A prospective cohort study. Scandinavian Journal of Public Health, 48, 726-732. https://doi. org/10.1177/1403494820902914

Arseneault, L., Moffitt, T. E., Caspi, A., Taylor, P. J., \& Silva, P. A. (2000). Mental disorders and violence in a total birth cohort: Results from the Dunedin Study. Archives of General Psychiatry, 57(10), 979-986. https://doi.org/10.1001/archpsyc.57.10.979

Ashworth, E., \& Humphrey, N. (2020). More than the sum of its parts: Cumulative risk effects on school functioning in middle childhood. British Journal of Education Psychology, 90, 43-61. https:// doi.org/10.1111/bjep. 12260

Bagwell, C. L., Newcomb, A. F., \& Bukowski, W. M. (1998). Preadolescent friendship and peer rejection as predictors of adult adjustment. Child Development, 69(1), 140-153.

Beeble, M. L., Bybee, D., Sullivan, C. M., \& Adams, A. E. (2009). Main, mediating, and moderating effects of social support on the well-being of survivors of intimate partner violence across 2 years. Journal of Consulting and Clinical Psychology, 77, 718729. https://doi.org/10.1037/a0016140

Bellis, M. A., Hardcastle, K., Ford, K., Hughes, K., Ashton, K., Quigg, Z., \& Butler, N. (2017). Does continuous trusted adult support in childhood impart life-course resilience against retrospective childhood experiences: A retrospective study on adult health-harming behaviours and mental well-being. BMC Psychiatry, 17(110), 1-12. https://doi.org/10.1186/s12888-017-1260-z

Bellis, M. A., Hughes, K., Ford, K., Hardcastle, K. A., Sharp, C. A., Wood, S., \& Davies, A. (2018). Adverse childhood experiences and sources of childhood resilience: A retrospective study of their combined relationships with child health and educational attendance. BMC Public Health, 18, 792. https://doi.org/10.1186/ s12889-018-5699-8

Bickel, R. (2007). Multilevel analysis for applied research: It's just regression. The Guilford Press.

Bowlby, J. (1982). Attachment and loss: Retrospect and prospect. American Journal of Orthopsychiatry, 52(4), 664-678. https:// doi.org/10.1111/j.1939-0025.1982.tb01456.x

Brewster, A. M., Martin, N. C., \& Garber, J. (2007). Predicting adolescents' organized activity involvement: The role of maternal 
depression history, family relationship quality, and adolescent cognitions. Journal of Research on Adolescence, 17, 221-224. https://doi.org/10.1111/j.1532-7795.2007.00520.x

Busching, R., \& Krahe, B. (2020). With a little help from their peers: The impact of classmates on adolescents' development of prosocial behavior. Journal of Youth and Adolescence, 49, 1849-1863. https://doi.org/10.1007/s10964-020-01260-8

Butler, N., Quigg, Z., \& Bellis, M. A. (2020). Cycles of violence in England and Wales: The contribution of childhood abuse to risk of violence revictimisation in adulthood. BMC Medicine. https:// doi.org/10.1186/s12916-020-01788-3

Chandon, J. S., Thomas, T., Gokhale, K. M., Bandyopadhyay, S., Taylor, J., \& Nirantharakumar, K. (2019). The burden of mental ill health associated with childhood maltreatment in the UK, using The Health Improvement Network database: A population-based retrospective cohort study. Lancet Psychiatry, 6, 926-934. https:// doi.org/10.1016/S2215-0366(19)30369-4

Chu, P. S., Saucier, D. A., \& Hafner, E. (2010). Meta-analysis of the relationships between social support and wellbeing in children and adolescents. Journal of Social and Clinical Psychology, 29(6), 624-645. https://doi.org/10.1521/jscp.2010.29.6.624

Clarke, A., Putz, R., Friede, T., Ashdown, J., Adi, Y., Martin, S., et al. (2010). Warwick-Edinburgh Mental Well-being Scale (WEMWBS) acceptability and validation in English and Scottis secondary school students (The WAVES Project). Edinburgh: NHS Health Scotland.

Collins, W. A., Maccoby, E. E., Steinberg, L., Hetherington, E. M., \& Bornstei, M. H. (2000). Contemporary research on parenting: The case for nature and nurture. American Psychologist, 55, 218-232. https://doi.org/10.1037/0003-066X.55.2.218

Criss, M. M., Pettit, G. S., Bates, J. E., Dodge, K. A., \& Lapp, A. L. (2002). Family adversity, positive peer relationships, and children's externalizing behavior: A longitudinal perspective on risk and resilience. Child Development, 73(4), 1220-1237. https://doi. org/10.1111/1467-8624.00468

Deighton, J., Humphrey, N., Belsky, J., Boehnke, J., Vostanis, P., \& Patalay, P. (2018). Longitudinal pathways between mental health difficulties and academic performance during middle childhood and early adolescence. British Journal of Developmental Psychology, 36, 110-126. https://doi.org/10.1111/bjdp.12218

Dube, S. R., Anda, R. F., Felitti, V. J., Chapman, D. P., Williamson, D. F., \& Giles, W. H. (2001). Childhood abuse, household dysfunction, and the risk of attempted suicide throughout the life span: Findings from the Adverse Childhood Experiences Study. JAMA, 286(24), 3089-3096. https://doi.org/10.1001/jama.286.24.3089

Edwards, V. J., Holden, G. W., Felitti, V. J., \& Anda, R. F. (2003). Relationship between multiple forms of childhood maltreatment and adult mental health in community respondents: Results from the adverse childhood experiences study. American Journal of Psychiatry, 160(8), 1453-1460. https://doi.org/10.1176/appi.ajp. 160.8 .1453

Egger, H. L., Costello, E. J., \& Angold, A. (2003). School refusal and psychiatric disorders: A community study. Journal of the American Academy of Child and Adolescent Psychiatry, 42, 797-807. https://doi.org/10.1097/01.CHI.0000046865.56865.79

Elborgen, E. B., \& Johnson, S. C. (2009). The intricate link between violence and mental disorder: Results from the National Epidemiological Survey on Alcohol and Related Conditions. Archives of General Psychiatry, 66(2), 152-161. https://doi.org/10.1001/ archgenpsychiatry.2008.537

Fombonne, E., Wostear, G., Cooper, V., Harrington, R., \& Rutter, M. (2001). The Maudsley long-term follow-up of child and adolescent depression. 1. psychiatric outcomes in adulthood. British Journal of Psychiatry, 179, 210-217. https://doi.org/10.1192/ bjp.179.3.210
Ford, T., Parker, C., Salim, J., Goodman, R., Logan, S., \& Henley, W. (2018). The relationship between exclusion from school and mental health: A secondary analysis of the British Child and Adolescent Mental Health Survey 2004 and 2007. Psychological Medicine, 48, 629-641. https://doi.org/10.1017/S003329171700215X

Fry, D., Fang, X., Elliott, S., Casey, T., Zheng, X., Li, J., ... McCluskey, G. (2018). The relationships between violence in childhood and educational outcomes: a global systematic review and metaanalysis. Child Abuse and Neglect, 75, 6-28. https://doi.org/10. 1016/j.chiabu.2017.06.021

Gilman, R., \& Huebner, E. S. (2003). A review of life satisfaction research with children and adolescents. School Psychology Quarterly, 18, 192-205. https://doi.org/10.1521/scpq.18.2.192.21858

Goodwin, R. D., Fergusson, D. M., \& Horwood, J. L. (2004). Association between anxiety disorders and substance use disorders among young persons: Results of a 21-year longitudinal study. Journal of Psychiatric Research, 38(3), 295-304. https://doi.org/10.1016/j. jpsychires.2003.09.002

Gore, F. M., Bloem, P. J., Patton, G. C., Ferguson, J., Joseph, V., Coffey, C., et al. (2011). Global burden of disease in young people aged 10-24 years: A systematic analysis. The Lancet, 377(9783), 2093-2102. https://doi.org/10.1016/S0140-6736(11)60512-6

Hardcastle, K., Bellis, M. A., Ford, K., Hughes, K., Garner, J., \& Rodriguez, G. R. (2018). Measuring the relationships between adverse childhood experiences and educational and employment success in England and Wales: Findings from a retrospective study. Public Health, 165, 106-116. https://doi.org/10.1016/j.puhe.2018.09.014

Harlow, H. F. (1958). The nature of love. American Psychologist, 13(12), 673-685. https://doi.org/10.1037/h0047884

Harris, J. R. (1995). Where is the child's environment? A group socialization theory of development. Psychological Review, 102, 50-75. https://doi.org/10.1037/0033-295X.102.3.458

Hartup, W. W. (1989). Social relationships and their developmental significance. American Psychologist, 44(2), 120-126. https://doi. org/10.1037/0003-066X.44.2.120

Hartup, W. W., \& Stevens, N. (1999). Friendships and adaptation across the life span. Current Directions in Psychological Science, 8(3), 76-79. https://doi.org/10.1111/1467-8721.00018

Heard-Garris, N., Davis, M. M., Szilagyi, M., \& Kan, K. (2018). Childhood adversity and parent perceptions of child resilience. BMC Pediatrics, 18(204), 1-10. https://doi.org/10.1186/ s12887-018-1170-3

Hughes, K., Bellis, M. A., Sethi, D., Andrew, R., Yon, Y., Wood, S., \& Zakhozha, V. (2019). Adverse childhood experiences, childhood relationships and associated substance use and mental health in young Europeans. The European Journal of Public Health, 29(4), 741-747. https://doi.org/10.1093/eurpub/ckz037

Hughes, K., Ford, K., Davies, A. R., Homolova, L., \& Bellis, M. A. (2018). Sources of resilience and their moderating relationships with harms from adverse childhood experiences. Public Health Wales.

Hughes, K., Ford, K., Kadel, R., Sharp, C. A., \& Bellis, M. A. (2020). Health and financial burden of adverse childhood experiences in England and Wales: A combined primary data study of five surveys. Public Health, 10(6), e036374. https://doi.org/10.1136/ bmjopen-2019-036374

Hughes, J., \& Kwok, O. (2007). Influence of teacher-student and parent-teacher relationships on lower achieving readers' engagement and achievement in the primary grades. Journal of Educational Psychology, 99, 39-51. https://doi.org/10.1037/0022-0663.99.1. 39

Hughes, K., Lowey, H., Quigg, Z., \& Bellis, M. A. (2016). Relationships between adverse childhood experiences and adult mental well-being: results from an English national household survey. BMC Public Health. https://doi.org/10.1186/s12889-016-2906-3

IBM. (2017). IBM SPSS advanced statistics 25. IBM Corp. 
Jimenez, M. E., Wade, R., Lin, Y., Morrow, L. M., \& Reichman, N. E. (2015). Adverse experiences in early childhood and kindergarten outcomes. Pediatrics, 137(2), 1839. https://doi.org/10.1542/peds. 2015-1839

Kandel, D. B., Johnson, J. G., Bird, H. R., Canino, G., Goodman, S. H., Lahey, B. B., \& Schwab-Stone, M. (1997). Psychiatric disorders associated with substance use among children and adolescents: Findings from the Methods for the Epidemiology of Child and Adolescent Mental Disorders (MECA) Study. Journal of Abnormal Child Psychology, 25(2), 121-132. https://doi.org/10.1023/a: 1025779412167

King, T., \& Fazel, M. (2019). Examining the mental health outcomes of peer-led school-based interventions on young people aged between 4 and 18 years old: A systematic review protocol. Systematic Reviews. https://doi.org/10.1186/s13643-019-1027-3

Kirby, N., Wright, B., \& Allgar, V. (2020). Child mental health and resilience in the context of socioeconomic disadvantage: Results from the Born in Bradford cohort study. European Child and Adolescent Psychiatry, 29, 467-477. https://doi.org/10.1007/ s00787-019-01348-y

Kreft, I. G., \& de Leeuw, J. (1998). Introducing multilevel modeling. Sage.

Laible, D., \& Thompson, R. A. (2007). Early socialization: A relationship perspective. In J. E. Grusec \& P. D. Hastings (Eds.), Handbook of socialization: Theory and research (pp. 181-207). The Guilford Press.

Lereya, S. T., Humphrey, N., Patalay, P., Wolpert, M., Bohnke, J. R., Macdougall, A., \& Deighton, J. (2016). The student resilience survey: Psychometric validation and associations with mental health. Child and Adolescent Psychiatry and Mental Health. https://doi. org/10.1186/s13034-016-0132-5

Levendosky, A. A., Huth-Bocks, A., \& Semel, M. A. (2002). Adolescent peer relationships and mental health functioning in families with domestic violence. Journal of Clinical Psychology, 31(2), 206-218. https://doi.org/10.1207/S15374424JCCP3102_06

Liddle, I., \& Carter, G. (2013). Emotional and psychological wellbeing in children: The standardisation of the Stirling children's wellbeing scale. Stirling Council.

Liddle, I., \& Carter, G. F. (2015). Emotional and psychological wellbeing in children: Development and validation of the Stirling Children's Well-being Scale. Educational Psychology in Practice, 31(2), 174-185. https://doi.org/10.1080/02667363.2015.1008409

Lindert, J., von Ehrenstein, O. S., Grashow, R., Gal, G., Braehler, E., \& Weisskopf, M. G. (2014). Sexual and physical abuse in childhood is associated with depression and anxiety over the life course: Systematic review and meta-analysis. International Journal of Public Health, 59, 359-372. https://doi.org/10.1007/s00038-013-0519-5

Lorber, M. F., O'Leary, S. G., \& Slep, A. M. (2011). An initial evaluation of the role of emotion and impulsivity in explaining racial/ ethnic differences in the use of corporal punishment. Developmental Psychology, 47(6), 1744-1749. https://doi.org/10.1037/ a0025344

Malindi, M. J., \& Machenjedze, N. (2012). The role of school engagement in strengthening resilience among male street children. South African Journal of Psychology, 42(1), 71-81. https://doi.org/10. 1177/008124631204200108

McLaughlin, K. A., Greif Green, J., Gruber, M. J., Sampson, N. A., Zaslavsky, A. M., \& Kessler, R. C. (2012). Childhood adversities and first onset of psychiatric disorders in a national sample of US adolescents. Archives of General Psychiatry, 69, 1151-1160. https://doi.org/10.1001/archgenpsychiatry.2011.2277

McLeod, J. D., Uemura, R., \& Rohrman, S. (2012). Adolescent mental health, behavior problems, and academic achievement. Journal of Health and Social Behavior, 53(4), 482-497. https://doi.org/10. $1177 / 0022146512462888$
McPherson, K. E., Kerr, S., McGee, E., Morgan, A., Cheater, F. M., McLean, J., \& Egan, J. (2014). The association between social capital and mental health and behavioural problems in children and adolescents: An integrative systematic review. BMC Psychology. https://doi.org/10.1186/2050-7283-2-7

Mendez, M., Durtschi, J., Neppl, T. K., \& Stith, S. (2017). Corporal punishment and externalizing behaviors in toddlers: The moderating role of positive and harsh parenting. Journal of Family Psychology, 30(8), 887-895. https://doi.org/10.1037/fam0000187

Morgan, A., Currie, C., Due, P., Nic Gabhain, S., Rasmussen, M., Samdal, O., \& Smith, R. (2007). Mental wellbeing in school-aged childen in Europe: associations with social cohesion and socioeconomic circumstances. Denmark: World Health Organization Regional Office for Europe.

Morrison, G., \& Allen, M. (2007). Promoting student resilience in school contexts. Theory into Practice, 46(2), 162-169. https:// doi.org/10.1080/00405840701233172

Morton, N., \& Browne, K. (1998). Theory and observation of attachment and its relation to child maltreatment: A review. Child Abuse, 22(11), 1093-1104. https://doi.org/10.1016/s01452134(98)00088-x

National Scientific Council on the Developing Child. (2015). Supportive relationships and active skill-building strengthen the foundations of resilience: Working paper no. 13. Retrieved from www. developingchild.harvard.edu

NHS Digital. (2018). Mental health of children and young people in England, 2017. NHS Digital. Retrieved from https://digital.nhs. uk/data-and-information/publications/statistical/mental-health-ofchildren-and-young-people-in-england/2017/2017

Oberle, E., Schonert-Reichl, K. A., \& Zumbo, B. D. (2011). Life satisfaction in early adolescence: Personal, neighbourhood, school, family, and peer influences. Journal of Youth and Adolescence, 40, 889-901. https://doi.org/10.1007/s10964-010-9599-1

Oldfield, J., Humphrey, N., \& Hebron, J. (2016). The role of parental and peer attachment relationships and school connectedness in predicting adolescent mental health outcomes. Child and Adolescent Mental Health, 21(1), 21-29. https://doi.org/10.1111/camh. 12108

Ostaszewski, K., \& Zimmerman, M. A. (2006). The effects of cumulative risks and promotive factors on urban adolescent alcohol and other drug use: A longitudinal study of resilience. American Journal of Community Psychology, 38, 237-249. https://doi.org/ 10.1007/s10464-006-9076-X

Paget, A., Parker, C., Heron, J., Logan, S., Henley, W., Emond, A., \& Ford, T. (2018). Which children and young people are excluded from school? Findings from a large British birth cohort study, the Avon Longitudinal Study of Parents and Children (ALSPAC). Child Care Health and Development, 44(2), 285-296. https://doi. org/10.1111/cch.12525

Patalay, P., \& Fitzsimons, E. (2017). Mental ill-health among children of the new century. Centre for Longitudinal Studies.

Patel, V., Flisher, A. J., Hetrick, S., \& McGorry, P. (2007). Mental health of young people: A global public-health challenge. The Lancet, 369(9569), 1302-1313. https://doi.org/10.1016/S01406736(07)60368-7

Pitchforth, J., Fahy, K., Ford, T., Wolpert, M., Viner, R. M., \& Hargreaves, D. S. (2018). Mental health and wellbeing trends among children and young people in the UK, 1995-2014: Analysis of repeated cross-sectional national health surveys. Psychological Medicine. https://doi.org/10.1017/S0033291718001757

Price, J. M. (1996). Friendship of maltreated children and adolescents: Contexts for expressing and modifying relationship history. The company they keep (pp. 262-285). Cambridge University Press.

Public Health England. (2016). Measuring and monitoring children and young people's mental wellbeing: A toolkit for schools and colleges. Anna Freud National Centre for Children and Families. 
Raposo, S. M., Mackenzie, C. S., Henriksen, C. A., \& Afifi, T. O. (2014). Time does not heal all wounds: Older adults who experienced childhood adversities have higher odds of mood, anxiety, and personality disorders. American Journal of Geriatric Psychiatry, 22(11), 1241-1250. https://doi.org/10.1016/j.jagp.2013. 04.009

Reef, J., Diamantopoulou, S., van Meurs, I., Verhulst, F. C., \& van der Ende, J. (2011). Developmental trajectories of child to adolescent externalizing behaviour and adult DSM-IV disorder: Results of a 24-year longitudinal study. Social Psychiatry and Psychiatric Epidemiology, 46(12), 1233-1241. https://doi.org/10.1007/ s00127-010-0297-9

Reitz, A. K., Zimmermann, J., Hutteman, R., Specht, J., \& Neyer, F. J. (2014). How peers make a difference: the role of peer groups and peer relationships in personality development. European Journal of Personality, 28, 279-288. https://doi.org/10.1002/per.1965

Rothon, C., Head, J., Klineberg, E., \& Stansfeld, S. (2011). Can social support protect bullied adolescents from adverse outcomes? A prospective study on the effects of bullying on the educational achievement and mental health of adolescents at secondary schools in East London. Journal of Adolescence. https://doi.org/ 10.1016/j.adolescence.2010.02.007

Rubin, K. H. (1990). Peer relationships and social skills in childhood: An international perspective. Human Development, 33(4), 221224. https://doi.org/10.1159/000276519

Schwartz, D., Dodge, K. A., Pettit, G. S., \& Bates, J. E. (2000). Friendship as a moderating factor in the pathway between early harsh home environment and later victimization in the peer group. Developmental Psychology, 36, 646-662. https://doi.org/10.1037/ 0012-1649.36.5.646

Sharkey, J. D., You, S., \& Schnoebelen, K. (2008). Relations among school assets, individual resilience, and student engagement for youth grouped by level of family functioning. Psychology in the Schools, 45(5), 402-418. https://doi.org/10.1002/pits.20305

Sibley, M. H., Pelham, W. E., Molina, B. S., Gnagy, E. M., Waschbusch, D. A., Biswas, A., \& Karch, K. M. (2011). The delinquency outcomes of boys with ADHD with and without comorbidity. Journal of Abnormal Child Psychology, 39(1), 21-32. https:// doi.org/10.1007/s10802-010-9443-9

Stith, S. M., Liu, T., Davies, C., Boykin, E. L., Alder, M. ., Harris, J. M., ... Dees, J. (2009). Risk factors in child maltreatment: a metaanalytic review of the literature. Aggression and Violent Behavior, 14(1), 13-29. https://doi.org/10.1037/fam0000187

Stoddard, S. A., Whiteside, L., Zimmerman, M. A., Cunningham, R. M., Chermack, S. T., \& Walton, M. (2013). The relationship between cumulative risk and promotive factors anad violent behavior among urban adolescents. American Journal of Community Psychology, 51, 57-65. https://doi.org/10.1007/ s10464-012-9541-7

Sylva, K., Melhuish, E., Sammons, P., Siraj-Blatchford, I., \& Taggart, B. (2008). Effective Pre-school and Primary Education 3-11 Project (EPPE 3-11) - final report from the primary phase: Preschool, school and family influences on children's development during key stage 2 (7-11). London: Department for Children Schools and Families.
Turner, H. A., Finkelhor, D., \& Ormrod, R. (2006). The effect of lifetime victimization on the mental health of children and adolescents. Social Science and Medicine, 62, 13-27. https://doi.org/10. 1016/j.socscimed.2005.05.030

United Nations. (2018, May 03). Mental health 'neglected issue' but key to achieving Global Goals, say UN chiefs. (United Nations) Retrieved March 13, 2021, from https://www.un.org/sustainabl edevelopment/blog/2018/05/mental-health-neglected-issue-butkey-to-achieving-global-goals-say-un-chiefs/

UK Parliament. (2020, January 15). Parliamentary Bills: Schools (Mental Health and Wellbeing) Bill. Retrieved March 03, 2021, from https://bills.parliament.uk/bills/2549

Vorhaus, L., \& Vorhaus, J. (2012). The impact of pupil behaviour and wellbeing on educational outcomes. Department for Education.

Wentzel, K. R. (1998). Social relationships and motivation in middle school: The role of parents, teachers, and peers. Journal of Educational Psychology, 90, 202-209. https://doi.org/10.1037/ 0022-0663.90.2.202

Werner, E. E. (2005). What can we learn about resilience from largescale longitudinal studies. In S. Goldstein \& R. B. Brooks (Eds.), Handbook of Resilience in Children (pp. 91-105). Springer.

Werner, E., \& Smith, R. (1989). Vulnerable but invincible: A longitudinal study of resilient children and youth. Adams, Bannister, and Cox.

Whitehead, R., Pringle, J., Scott, E., Milne, D., \& McAteer, J. (2019). The relationship between a trusted adult and adolescent health and education outcomes. NHS Health Scotland.

Wood, J. J., Lynne-Landsman, D. S., Langer, D. A., Wood, P. A., Clark, S. L., Eddy, J. M., et al. (2012). School attendance problems and youth psychopathology: Structural cross-lagged regression models in three longitudinal data sets. Child Development, 83, 351-366. https://doi.org/10.1111/j.1467-8624.2011.01677.x

Woolley, M., \& Bowen, G. (2007). In the context of risk: Supportive adults and the school engagement of middle school students. Family Relations, 56(1), 92-104. https://doi.org/10.1111/j.1741-3729. 2007.00442.x

World Health Organization. (2012). Adolescent mental health. World Health Organization.

World Health Organization Regional Office for Europe. (2018). Adolescent mental health in the European Region. World Health Organization Regional Office for Europe.

Yoshikawa, H. (1994). Prevention as cumulative protection: Effects of early family support and education on chronic delinquency and its risks. Psychology Bulletin, 115(1), 28-54. https://doi.org/10. 1037/0033-2909.115.1.28

Zimrin, H. (1986). A profile of survival. Child Abuse and Neglect, 10, 339-349. https://doi.org/10.1016/0145-2134(86)90009-8

Publisher's Note Springer Nature remains neutral with regard to jurisdictional claims in published maps and institutional affiliations. 